\title{
Digestive System Melanoma
}

National Cancer Institute

\section{Source}

National Cancer Institute. Digestive System Melanoma. NCI Thesaurus. Code C7091.

A melanoma that arises from any part of the digestive system. 